\title{
Physiologic Responses to Infrarenal Aortic Cross-Clamping during Laparoscopic or Conventional Vascular Surgery in Experimental Animal Model: Comparative Study
}

\author{
María F. Martín-Cancho, Verónica Crisóstomo, Federico Soria, Carmen Calles, \\ Francisco M. Sánchez-Margallo, Idoia Díaz-Güemes, and Jesús Usón-Gargallo \\ Minimally Invasive Surgery Centre Jesús Usón, Carretera Nac. 521, Km 41.8, 10071 Cáceres, Spain \\ Correspondence should be addressed to María F. Martín-Cancho, mmartinc@ccmi.es
}

Received 18 June 2007; Revised 26 October 2007; Accepted 26 February 2008

Recommended by Gilbert Blaise

\begin{abstract}
The aim of this study was to compare the hemodynamic and ventilatory effects of prolonged infrarenal aortic cross-clamping in pigs undergoing either laparotomy or laparoscopy. 18 pigs were used for this study. Infrarenal aortic crossclamping was performed for 60 minutes in groups I (laparotomy, $n=6$ ) and II (laparoscopy, $n=6$ ). Group III (laparoscopy, $n=6$ ) underwent a 120minute long pneumoperitoneum in absence of aortic clamping (sham group). Ventilatory and hemodynamic parameters and renal function were serially determined in all groups. A significant decrease in $\mathrm{pH}$ and significant increase in $\mathrm{PaCO}_{2}$ were observed in group II, whereas no changes in these parameters were seen in group I and III. All variables returned to values similar to baseline in groups I and II 60 minutes after declamping. A significant increase in renal resistive index was evidenced during laparoscopy, with significantly higher values seen in Group II. Thus a synergic effect of pneumoperitoneum and aortic cross-clamping was seen in this study. These two factors together cause decreased renal perfusion and acidosis, thus negatively affecting the patient's general state during this type of surgery.
\end{abstract}

Copyright ( 92008 María F. Martín-Cancho et al. This is an open access article distributed under the Creative Commons Attribution License, which permits unrestricted use, distribution, and reproduction in any medium, provided the original work is properly cited.

\section{INTRODUCTION}

Abdominal aortic surgery has improved greatly during the last 50 years, mainly thanks to advances in both anesthetic and surgical techniques. Abdominal laparoscopy is normally perceived to be associated with fewer risks [1]. However, clinicians should be aware of inherent dangers such as gaseous embolization, a potential inability to control hemorrhage, an increase in carbon dioxide arterial partial pressure, and changes in arterial blood pressure and heart rate. The hemodynamic and respiratory alterations associated with abdominal laparoscopy are caused by the high intra-abdominal pressure brought over by pneumoperitoneum creation. The most relevant hemodynamic changes are a decrease in venous return secondary to IVC compression and increases in central venous pressure and arterial blood pressure in absence of heart rate changes. Regarding respiratory adjustments, cranial displacement of the diaphragm causes a restrictive respiratory syndrome with decreased pulmonary compliance and increased pulmonary pressures and inspiratory peak $[2,3]$.

When used in the management of aortic diseases, the laparoscopic approach poses further complications and risks that must be addressed, such as the long aortic crossclamping and surgical times [4]. Moreover, aortic crossclamping in itself causes certain hemodynamic changes, whose effects must be taken into account along with the alterations secondary to laparoscopy. Previous human studies [4] reported severe problems during aortic declamping and very prolonged anesthetic recovery times.

Despite recent reports describing the feasibility of the laparoscopic approach for the management of aortic occlusive and aneurismatic disease [5-8] these studies focused on the surgical technique and its technical feasibility, without assessing hemodynamic and ventilatory stability or the patient's recovery from the procedure.

Data compiled in a review written by Gelman in 1995 [9] demonstrated that aortic cross-clamping and declamping 
are associated to severe disturbances in homeostasis in virtually all body systems. In experimental and clinical settings, cardiovascular responses to aortic cross-clamping are characterized by increases in proximal arterial pressure and systemic vascular resistance, while cardiac output decreases [9-12].

Prior studies by Byrne et al. [13] assessed physiological responses to laparoscopic aortobifemoral bypass surgery, while Alfonsi et al. [14] focused their works on the evaluation of cardiac function during intraperitoneal $\mathrm{CO}_{2}$ insufflation for aortic surgery. However, those studies did not evaluate the combination of the effects of aortic cross-clamping and pneumoperitoneum during aortic surgery. Moreover, the anesthetic protocol used in Byrne's study [13] is no longer in clinical use in hospitals nowadays.

We have found no studies evaluating pathophysiologic changes secondary to cross-clamping and declamping of the abdominal aorta during vascular laparoscopic surgery. With this in mind, we consider that the evaluation of physiologic changes occurring during infrarenal aortic surgery, whether using conventional surgery or laparoscopic techniques, is extremely important in order to determine whether the observed hemodynamic changes can be attributed to pneumoperitoneum or aortic cross-clamping alone or to the combined effect of these two factors. Understanding these alterations will enable clinicians to improve the quality of anesthesia when performing this kind of surgery. In our opinion, laparoscopic aortic cross-clamping may cause physiological changes precluding the safe use of this technique in all patients.

\section{MATERIALS AND METHODS}

\subsection{Animals}

The experimental protocol was approved by the Institutional Ethical Committee for Animal Research. Eighteen healthy female large white pigs were used. Mean weight was $30.8 \pm$ $2.0 \mathrm{~kg}$.

\subsection{Anesthesia}

One day prior to the experimental anesthetic episode, each pig was anesthetized with sevoflurane (Sevorane, Abbott Laboratories, Madrid, Spain), and a 20-standard wire gauge catheter was placed in the carotid artery and fixed to the skin. Similarly, on that same day a 4 Fr. vascular sheath was placed in the external jugular vein using the Seldinger technique. Pigs were randomly assigned to 3 groups. Groups I $(n=6)$ and II $(n=6)$ underwent aortic cross-clamping through either laparotomy in Group I or laparoscopy in Group II. Animals belonging to Group III underwent a 120-minute long laparoscopy in absence of aortic intervention (sham group). Food, but not water, was withheld for 8 hours prior to surgery. Body temperature was maintained stable at 37$38^{\circ} \mathrm{C}$, using a thermal blanket (Astopad system, Stihler electronic GMBH. Stuttgart, Germany) and administering tempered fluids.
Animals were premedicated with IM diazepam (Valium, Roche Farma, Madrid, Spain) $(0.1 \mathrm{mg} / \mathrm{kg})$ and ketamine (Ketolar, Pfizer, Madrid, Spain) (10 mg/kg). Anesthesia was induced with propofol ( $4 \mathrm{mg} / \mathrm{kg})$, which was administered after oxygenation by facial mask with $100 \%$ oxygen for 3 minutes. When lack of jaw tone, loss of swallowing, lack of head shaking, loss of palpebral and pain reflexes, and ventromedial rotation of the eyes were all detected, endotracheal intubation was performed with the tube connected to a semiclosed circular anesthetic circuit attached to a ventilator (Ventilator 7800, Ohmeda, Madrid, Spain). Sevoflurane administration started at 5\%, which enabled us to rapidly achieve 1.25 MAC (1MAC = 2.66\%) [10] with an oxygen flow rate of $3 \mathrm{~L} / \mathrm{min}$. Once $1.25 \mathrm{MAC}$ was reached $(3.3 \% \mathrm{Et}$ sevoflurane), the vaporizer setting was adjusted as needed to maintain this concentration. Muscle relaxation was obtained by injection of vecuronium $(0.1 \mathrm{mg} / \mathrm{kg})$ (Norcuron, Organon Española, Barcelona Spain) every 30 minutes. A bolus $(5 \mu \mathrm{g} / \mathrm{kg})$ of fentanyl (Fentanest, Roche, Madrid, Spain) was administered every 30 minutes. Systemic heparinization (Heparina Rovi 5\%, laboratorios farmacéuticos Rovi SA, Madrid, Spain) was administered (150 UI/kg) 5 minutes prior to aortic cross-clamping. Postoperative analgesia was assured by administering $10 \mu \mathrm{g} / \mathrm{Kg}$ of IM Buprenorphine (Buprex, Schering-Plough, Madrid, Spain) every 8 hours.

Intermittent positive pressure ventilation was used during the procedure to maintain end-tidal $\mathrm{CO}_{2}$ concentration between 35 to $45 \mathrm{mmHg}$, with a tidal volume of $10 \mathrm{~mL} / \mathrm{kg}$ in the open surgery group and ranging between $13-15 \mathrm{~mL} / \mathrm{kg}$ in the laparoscopy groups.

During surgery, continuous infusion of Ringer-lactate solution (Ringer-lactato, Braun, Barcelona, Spain) at a rate of $10 \mathrm{~mL} / \mathrm{kg} / \mathrm{h}$ was administered. $500 \mathrm{~mL}$ of a colloid solution (hydroxyethyl starch, Voluven 6\%, Fresenius Kabi, Barcelona, Spain) was administered five minutes before declamping in every animal. At the end of the surgery, the vaporizer was switched off and fresh gas flow rate was increased to $10 \mathrm{~L} / \mathrm{min}$ of $100 \%$ oxygen. Pigs were extubated when they regained swallowing reflexes and considered recovered and fully conscious when the attending anesthesiologists recorded their ability to stand and walk.

\subsection{Surgical procedures}

For pigs undergoing laparotomy, a standard ventral midline approach was used (Group I). For pigs undergoing laparoscopy (groups II and III), $310 \mathrm{~mm}$ laparoscopic ports were inserted. Pneumoperitoneum was created by insufflating $\mathrm{CO}_{2}$ into the abdominal cavity; intra-abdominal pressure was maintained at 12 to $14 \mathrm{~mm} \mathrm{Hg}$ in both groups (Group II and III). In Group III, $\mathrm{CO}_{2}$ pneumoperitoneum was maintained for 120 minutes, which was considered the minimum time needed to complete the cross-clamping procedure performed in Group II.

In animals belonging to groups I and II, aortic dissection was performed from the origin of the renal arteries to the origin of the caudal mesenteric artery, and all lumbar arteries 
in the target aortic segment were temporarily occluded. The aorta was then cross-clamped immediately below the origin of the caudal renal artery and immediately cranial to the inferior mesenteric artery. Aortic occlusion was maintained for 60 minutes.

These procedures were always performed by the same surgical team using the same technique in order to achieve reproducible stimulation.

\subsection{Monitoring}

BIS (A-1050TM, version 3.05.05, Aspect Medical Systems Inc, Natick, Mass, USA) was registered using a previously described electrodes montage [15]. Electrocardiography (Hewlett Packard model 86S, Hewlett Packard, Geneva, Switzerland) (lead II) and pulse oximetry with a probe (Clip Tip sensor, Oximeter Sensor, Datex-Ohmeda, Louisville, Colo, USA) placed on the tongue were monitored. Other parameters registered were rectal temperature, tidal volume, end-tidal concentration of sevoflurane, end-tidal $\mathrm{CO}_{2}$ concentration, and respiratory rate (Ohmeda RGM 5250, Ohmeda, Madrid, Spain). Muscle relaxation was observed and monitored by train-of-four (TOF) (TOF-Guard, Biometer International A/S, Odense, Denmark).

Arterial blood pressure, central venous pressure and heart rate were also measured using a blood pressure module (Hewlett Packard Press M 1006B, Hewlett Packard, Geneva, Switzerland) connected to a system for monitoring hemodynamic variables.

We measured hemodynamic variables in real time using the PulseCO continuous cardiac output monitoring system (LiDCO Ltd): cardiac output (CO), stroke volume (SV) and systemic vascular resistance (SVR). The system was calibrated using the lithium dilution technique [16] for cardiac output measurement at a lithium dosage of $0.04 \mathrm{~mL} / \mathrm{kg}$.

\subsection{Arterial blood gasometry assays}

Through the carotid artery, arterial blood was sampled at different times (see below). At each interval, $0.5 \mathrm{~mL}$ of blood were collected using a prefilled heparin syringe. $\mathrm{pH}, \mathrm{PaCO}_{2}$, $\mathrm{PaO}_{2}$ and bicarbonate (CO3H-) were measured using the arterial gas analyzer (Radiometer Medical, model ABL77, Copenhagen, Denmark).

\subsection{Renal function tests}

Urine production was registered every 30 minutes, along with seric urea and creatinine. The Pourcelot or renal resistive index was also determined at these times $(\mathrm{RI}=$ peak systolic velocity - end diastolic velocity/peak systolic velocity) at the arcuate arteries of the corticomedullary junction, using a Panther 2002 (B\&K Medical, Herlev, Denmark) ultrasound scanner with a conventional probe $(5,5 \mathrm{MHz})$ for transcutaneous examination and a $9.8 \mathrm{~mm}$ laparoscopic probe $(6,5 \mathrm{MHz})$ for the laparoscopic approach.

\subsection{Data processing}

All data were expressed as mean \pm SD at the following times:

T1 baseline (immediately after connecting the patient to the monitoring systems prior to surgery;

T2 Groups I and II, 5 minutes before cross-clamping. Group III pneumoperitoneum establishment;

T3 Groups I and II, 30 minutes after cross-clamping. Group III 60 minutes after pneumoperitoneum creation;

T4 Groups I and II, 60 minutes after cross-clamping. Group III, 120 minutes after pneumoperitoneum creation;

T5 Groups I and II, 5 minutes after declamping or 5 minutes after the end of pneumoperitoneum in Group III;

T6 Groups I and II, 30 minutes after declamping or 30 minutes after the end of pneumoperitoneum in Group III;

T7 Groups I and II, 60 minutes after declamping or 60 minutes after the end of pneumoperitoneum in Group III.

A Kolmogorov Smirnov test [17] was used to determine that data were normally distributed. Changes in ventilatory and hemodynamic variables at each time point were analyzed using ANOVA for repeated measures followed by the Tukey test to examine intergroup deviation from control values. Recovery times were analyzed by use of ANOVA, using the group (laparotomy with cross-clamping, laparoscopy with crossclamping, or laparoscopy alone) as the independent variable. Values of $P<.05$ were considered significant (SPSS 14.0 statistical package for Windows, SPSS Inc, Chicago, Ill, USA).

\section{RESULTS}

Mean \pm SD duration of anesthesia was $216 \pm 15$ minutes in the animals that underwent laparotomy, $367 \pm 24$ minutes in the laparoscopic cross-clamping group and $195 \pm 26$ minutes in Group III. The difference between groups I and II was mainly attributable to the different time needed to complete aortic dissection ( $12 \pm 4$ minutes for pigs undergoing laparotomy versus $39 \pm 4$ minutes for pigs undergoing laparoscopy) plus the time needed for placing the lumbar clips and the aortic clamps.

$\mathrm{SpO}_{2}$ was $>97 \%$ and $\mathrm{EtCO}_{2}$ was maintained between 35 to $40 \mathrm{mmHg}$ in all pigs. Blood loss was minimal for all procedures.

Anesthetic depth, as determined by BIS [18] and clinical observation was consistent with a surgical plane of anesthesia.

The changes observed in all the measured variables are reflected in Tables 1, 2, 3, 4, 5, and 6. In brief, these changes are summarized below.

Immediate and significant increases in ABP and SRV and decreases in CO and SV following aortic cross-clamping, without any concurrent significant changes to CVP or heart rate, were seen in groups I and II (Tables 1, 2, and 3). After declamping (T5), a significant increase in CO and SV and a significant decrease in ABP and SVR were also observed. 
TABLE 1: Heart rate and mean arterial blood pressure in pigs anesthetized with sevoflurane, fentanyl, and vecuronium and undergoing aortic cross-clamping through laparotomy (Group I) or laparoscopy with (Group II) or without aortic cross-clamping (Group III).

\begin{tabular}{|c|c|c|c|c|c|c|}
\hline \multirow[b]{2}{*}{ Times } & \multicolumn{3}{|c|}{ Heart rate (beats/min) } & \multicolumn{3}{|c|}{ Mean arterial blood pressure ( $\mathrm{mmHg})$} \\
\hline & Group I & Group II & Group III & Group I & Group II & Group III \\
\hline T1 & $79.6 \pm 11.7$ & $81.6 \pm 11.0$ & $76.5 \pm 3.1$ & $68.2 \pm 7.3$ & $57.6 \pm 1.8$ & $65.7 \pm 10.6$ \\
\hline $\mathrm{T} 2$ & $78.8 \pm 14.4$ & $85.8 \pm 12.3$ & $78.5 \pm 4.2$ & $65.0 \pm 7.4$ & $73.0 \pm 6.4^{*}$ & $81.7 \pm 10.1^{*}$ \\
\hline T3 & $78.7 \pm 14.4$ & $86.8 \pm 14.8$ & $78.7 \pm 4.1$ & $78.8 \pm 13.8^{*}$ & $77.0 \pm 9.1^{*}$ & $84.3 \pm 8.5^{*}$ \\
\hline $\mathrm{T} 4$ & $82.8 \pm 18.7$ & $88.0 \pm 18.0$ & $78.0 \pm 6.2$ & $83.2 \pm 15.8^{*}$ & $78.8 \pm 8.2^{*}$ & $85.2 \pm 7.5^{*}$ \\
\hline T5 & $89.8 \pm 21.2$ & $100.0 \pm 22.7$ & $78.5 \pm 7.0$ & $52.6 \pm 12.0^{*}$ & $61.8 \pm 9.3$ & $76.0 \pm 15.7$ \\
\hline T6 & $90.7 \pm 15.3$ & $94.0 \pm 16.2$ & $80.2 \pm 8.3$ & $64.7 \pm 7.7$ & $52.6 \pm 4.9$ & $68.8 \pm 18.1$ \\
\hline T7 & $93.0 \pm 15.3$ & $91.4 \pm 11.9$ & $78.3 \pm 7.4$ & $64.8 \pm 8.0$ & $53.6 \pm 5.4$ & $68.7 \pm 16.2$ \\
\hline
\end{tabular}

Data are expressed as mean \pm SD.

* Significant changes from baseline $(P<.05)$.

TABLe 2: Central venous pressure (CVP), cardiac output (CO) in pigs anesthetized with sevoflurane, fentanyl, and vecuronium and undergoing aortic cross-clamping through laparotomy (Group I) or laparoscopy with (Group II) or without aortic cross-clamping (Group III).

\begin{tabular}{|c|c|c|c|c|c|c|}
\hline \multirow[b]{2}{*}{ Times } & \multicolumn{3}{|c|}{$\operatorname{CVP}\left(\mathrm{cm} \mathrm{H}_{2} \mathrm{O}\right)$} & \multicolumn{3}{|c|}{$\mathrm{CO}(\mathrm{L} / \mathrm{min})$} \\
\hline & Group I & Group II & Group III & Group I & Group II & Group III \\
\hline T1 & $5.3 \pm 1.4$ & $3.6 \pm 0.5$ & $4.0 \pm 0.5$ & $4.16 \pm 0.61$ & $4.06 \pm 0.62$ & $3.57 \pm 0.48$ \\
\hline $\mathrm{T} 2$ & $5.0 \pm 1.8$ & $6.4 \pm 3.2^{*}$ & $7.3 \pm 1.2^{*}$ & $4.13 \pm 0.52$ & $3.49 \pm 0.73$ & $3.08 \pm 0.36$ \\
\hline $\mathrm{T} 3$ & $4.2 \pm 2.1$ & $6.2 \pm 3.4^{*}$ & $6.6 \pm 0.4^{*}$ & $4.12 \pm 1.04$ & $2.80 \pm 1.21^{*}$ & $2.67 \pm 0.15^{*}$ \\
\hline $\mathrm{T} 4$ & $5.8 \pm 2.7$ & $4.8 \pm 2.5$ & $5.5 \pm 0.6$ & $3.40 \pm 1.21$ & $3.12 \pm 1.42^{*}$ & $2.88 \pm 0.26$ \\
\hline T5 & $4.8 \pm 3.2$ & $4.8 \pm 3.5$ & $3.4 \pm 1.6$ & $6.50 \pm 2.12^{*}$ & $5.50 \pm 1.88^{*}$ & $3.18 \pm 0.40^{\dagger}$ \\
\hline T6 & $5.5 \pm 3.0$ & $1.6 \pm 0.5$ & $2.7 \pm 0.9$ & $5.28 \pm 1.67$ & $4.88 \pm 1.86$ & $3.40 \pm 0.67^{\dagger}$ \\
\hline $\mathrm{T} 7$ & $5.8 \pm 2.6$ & $2.6 \pm 1.5$ & $2.6 \pm 1.5$ & $4.90 \pm 1.11$ & $4.54 \pm 1.01$ & $3.45 \pm 0.60^{\dagger}$ \\
\hline
\end{tabular}

Data are expressed as mean \pm SD.

* Significant changes from baseline $(P<.05)$.

In Groups II and III, pneumoperitoneum caused a significant increase in CVP, ABP, and SVR along with decreased CO (Tables 1, 2, and 3). In Group II a significant increase in $\mathrm{PaCO}_{2}$ and a significant decrease in $\mathrm{pH}$ (Table 4) were seen.

No significant changes in $\mathrm{pH}$ or arterial gasometry were caused by clamping or declamping in Group I, whereas in Group II a further significant decrease in $\mathrm{pH}$ values was seen during cross-clamping, whilst $\mathrm{HCO} 3$ was kept over $26 \mathrm{mmol} / \mathrm{l}$ during cross-clamping and declamping in order to compensate for the acidosis (Tables 4 and 5).

No significant changes in urea or creatinine were evidenced between groups. However, significant $(P<.05)$ increases in the RI were seen during infrarenal aortic crossclamping in Group II (laparoscopy) (Table 6) and during pneumoperitoneum creation in Group III, with the increase being significantly greater in Group II than in Group III. Similarly, urine production was decreased by 35\% during laparoscopic clamping when compared to cross-clamping by open surgery, and by 30\% during laparoscopic crossclamping when compared to laparoscopy in absence of aortic cross-clamping.

60 minutes after declamping, all the studied variables had returned to baseline values in all groups. No significant differences were observed between groups in regard to recovery times except for the time to standing which was signif- icantly lower in groups II and III (pigs that had undergone laparoscopy) (Table 7).

\section{DISCUSSION}

While the systemic cardiovascular consequences of infrarenal aortic cross-clamping during aortic abdominal surgery are well documented in both humans [9] and pig [19], and have been reported to be very similar (this animal model reproduces the changes observed in humans), its repercussions during laparoscopic surgery have not been reported.

In the present study, pneumoperitoneum caused a significant increase in arterial blood pressure and systemic vascular resistance. Generally speaking, the higher arterial blood pressure observed may be attributed to the increase in intraabdominal pressure caused by pneumoperitoneum, which gives rise to increased systemic vascular resistance and arterial blood pressure to compensate for the decrease in cardiac output secondary to the decreased venous return [2]. However other authors have reported that neither increased intra-abdominal pressure nor plasma accumulation of carbon dioxide influences cardiac output $[20,21]$. In this study, a decrease in cardiac output was evidenced immediately after pneumoperitoneum creation. In our opinion, hypertension may also be caused by any of three factors: mechanical 
TABLE 3: Systolic volume (SV) and and systemic vascular resistance (SVR) in pigs anesthetized with sevoflurane, fentanyl, and vecuronium and undergoing aortic cross-clamping through laparotomy (Group I) or laparoscopy with (Group II) or without aortic cross-clamping (Group III).

\begin{tabular}{|c|c|c|c|c|c|c|}
\hline \multirow[b]{2}{*}{ Times } & \multicolumn{3}{|c|}{$\mathrm{SV}(\mathrm{mL})$} & \multicolumn{3}{|c|}{ SVR (Dyn s/cm5) } \\
\hline & Group I & Group II & Group III & Group I & Group II & Group III \\
\hline $\mathrm{T} 1$ & $49.0 \pm 10.5$ & $42.2 \pm 20.0$ & $42.5 \pm 0.5$ & $1556 \pm 370$ & $1460 \pm 359$ & $1735 \pm 202$ \\
\hline $\mathrm{T} 2$ & $45.8 \pm 9.7$ & $35.2 \pm 10.3$ & $41.5 \pm 3.5$ & $1509 \pm 394$ & $1940 \pm 529^{*}$ & $2098 \pm 133^{*}$ \\
\hline T3 & $38.0 \pm 11.1$ & $37.2 \pm 13.6$ & $36.8 \pm 2.6$ & $2083 \pm 456^{*}$ & $2080 \pm 957^{*}$ & $2455 \pm 397^{*}$ \\
\hline $\mathrm{T} 4$ & $39.5 \pm 15.4$ & $38.0 \pm 12.6$ & $36.0 \pm 2.4$ & $2100 \pm 610^{*}$ & $2010 \pm 1016^{*}$ & $2508 \pm 469^{*}$ \\
\hline T5 & $62.2 \pm 25.4^{*}$ & $62.0 \pm 33.3^{*}$ & $44.0 \pm 5.5$ & $933 \pm 513^{*}$ & $1160 \pm 290$ & $1926 \pm 410$ \\
\hline T6 & $51.5 \pm 17.7$ & $43.0 \pm 33.9$ & $41.0 \pm 1.5$ & $1208 \pm 483$ & $1230 \pm 256$ & $2032 \pm 482$ \\
\hline T7 & $52.3 \pm 14.5$ & $45.6 \pm 15.9$ & $42.7 \pm 1.9$ & $1361 \pm 636$ & $1320 \pm 97$ & $1880 \pm 337$ \\
\hline
\end{tabular}

*Significant changes from baseline $(P<.05)$.

TABLE 4: Acid-base balance in pigs anesthetized with sevoflurane, fentanyl, and vecuronium and undergoing aortic cross-clamping through laparotomy (Group I) or laparoscopy with (Group II) or without aortic cross-clamping (Group III).

\begin{tabular}{|c|c|c|c|c|c|c|}
\hline \multirow[b]{2}{*}{ Times } & \multicolumn{3}{|c|}{$\mathrm{pH}$} & \multicolumn{3}{|c|}{$\mathrm{CO} 3 \mathrm{H}-(\mathrm{mmol} / \mathrm{L})$} \\
\hline & Group I & Group II & Group III & Group I & Group II & Group III \\
\hline $\mathrm{T} 1$ & $7.48 \pm 0.01$ & $7.47 \pm 0.01$ & $7.40 \pm 0.73$ & $26.7 \pm 3.3$ & $31.2 \pm 1.1$ & $30.1 \pm 0.9$ \\
\hline $\mathrm{T} 2$ & $7.43 \pm 0.02$ & $7.32 \pm 0.07$ & $7.40 \pm 0.04$ & $23.1 \pm 7.3$ & $27.4 \pm 5.7^{\times}$ & $30.0 \pm 1.4^{\times}$ \\
\hline $\mathrm{T} 3$ & $7.46 \pm 0.04$ & $7.27 \pm 0.16^{* \dagger}$ & $7.40 \pm 0.5$ & $20.6 \pm 4.3$ & $31.2 \pm 3.5^{\times}$ & $31.0 \pm 1.5^{\times}$ \\
\hline $\mathrm{T} 4$ & $7.46 \pm 0.05$ & $7.28 \pm 0.17^{* \dagger}$ & $7.40 \pm 0.1$ & $26.6 \pm 2.3$ & $33.8 \pm 2.3^{\times}$ & $30.8 \pm 1.3^{\times}$ \\
\hline T5 & $7.40 \pm 0.06$ & $7.22 \pm 0.18^{* \dagger}$ & $7.43 \pm 0.1$ & $24.1 \pm 3.4$ & $29.1 \pm 7.1^{\times}$ & $30.3 \pm 1.7^{x}$ \\
\hline $\mathrm{T} 6$ & $7.41 \pm 0.06$ & $7.34 \pm 0.07$ & $7.38 \pm 0.6$ & $24.7 \pm 3.2$ & $32.8 \pm 3.6^{\times}$ & $30.0 \pm 1.6^{\times}$ \\
\hline T7 & $7.38 \pm 0.01$ & $7.32 \pm 0.07$ & $7.34 \pm 0.1$ & $21.5 \pm 7.6$ & $32.5 \pm 4.0^{\times}$ & $30.3 \pm 1.6^{\times}$ \\
\hline
\end{tabular}

${ }^{*}$ Significant changes from baseline $(P<.05)$.

${ }^{\dagger}$ Significantly $(P<.05)$ different from values for pigs undergoing laparoscopy and cross-clamping.

${ }^{\times}$Significantly $(P<.05)$ different from values for pigs undergoing laparoscopy.

TABLE 5: Acid-base balance in pigs anesthetized with sevoflurane, fentanyl, and vecuronium and undergoing aortic cross-clamping through laparotomy (Group I) or laparoscopy with (Group II) or without aortic cross-clamping (Group III).

\begin{tabular}{|c|c|c|c|c|c|c|}
\hline \multirow[b]{2}{*}{ Times } & \multicolumn{3}{|c|}{$\mathrm{PaCO}_{2}(\mathrm{mmHg})$} & \multicolumn{3}{|c|}{$\mathrm{PaO}_{2}(\mathrm{mmHg})$} \\
\hline & Group I & Group $\mathrm{II}^{\dagger}$ & Group III & Group I & Group II & Group III \\
\hline $\mathrm{T} 1$ & $36.0 \pm 5.0$ & $41.1 \pm 3.7$ & $38.0 \pm 2.4$ & $487.8 \pm 99.3$ & $574.2 \pm 81.1$ & $501.2 \pm 41.7$ \\
\hline $\mathrm{T} 2$ & $33.0 \pm 9.2$ & $45.6 \pm 6.4$ & $43.0 \pm 6.5$ & $447.3 \pm 111.7$ & $370.6 \pm 88.2^{*}$ & $495.7 \pm 37.3$ \\
\hline T3 & $30.7 \pm 6.1$ & $48.1 \pm 3.8^{*}$ & $43.0 \pm 3.9$ & $443.7 \pm 34.8$ & $399.8 \pm 96.3^{*}$ & $479.0 \pm 33.2$ \\
\hline $\mathrm{T} 4$ & $37.5 \pm 6.9$ & $51.6 \pm 2.3^{*}$ & $43.7 \pm 3.0$ & $501.7 \pm 64.9$ & $392.6 \pm 110.5^{*}$ & $456.7 \pm 48.6$ \\
\hline T5 & $39.5 \pm 7.2$ & $49.0 \pm 4.4^{*}$ & $42.2 \pm 2.2$ & $497.0 \pm 58.2$ & $458.2 \pm 106.2$ & $445.0 \pm 47.6$ \\
\hline T6 & $37.8 \pm 7.0$ & $48.6 \pm 4.0^{*}$ & $39.2 \pm 2.2$ & $481.0 \pm 72.7$ & $440.0 \pm 105.4$ & $448.7 \pm 26.6$ \\
\hline T7 & $38.5 \pm 8.5$ & $46.0 \pm 2.2$ & $38.0 \pm 2.3$ & $434.3 \pm 76.9$ & $452.0 \pm 106.9$ & $462.0 \pm 16.9$ \\
\hline
\end{tabular}

Data are expressed as mean \pm SD.

${ }^{\dagger}$ Significantly $(P<.05)$ different from values obtained for pigs undergoing laparoscopy and cross-clamping.

* Significant changes from baseline within each group $(P<.05)$.

TABLE 6: Renal resistive index values obtained thorough the study.

\begin{tabular}{lcccccc}
\hline & T1 & \multicolumn{1}{c}{ T2 } & \multicolumn{1}{c}{ T3 } & T4 & T5 \\
\hline Group I & $0.48 \pm 0.03$ & - & $0.58 \pm 0.11$ & $0.63 \pm 0.07$ & $0.56 \pm 0.10$ & $0.53 \pm 0.10$ \\
Group II & $0.53 \pm 0.10$ & $0.69 \pm 0.05^{* \dagger}$ & $0.69 \pm 0.06^{* \dagger}$ & $0.68 \pm 0.08^{* \dagger}$ & $0.68 \pm 0.02^{* \dagger}$ & $0.56 \pm 0.02$ \\
Group III & $0.49 \pm 0.03$ & $0.58 \pm 0.03^{*}$ & $0.58 \pm 0.11^{*}$ & $0.64 \pm 0.03^{*}$ & $0.60 \pm 0.10^{*}$ & $0.49 \pm 0.02$ \\
\hline
\end{tabular}

${ }^{\dagger}$ Significantly $(P<.05)$ different from values obtained for pigs undergoing laparoscopy and cross-clamping.

* Significant changes from baseline within each group $(P<.05)$. 
TABLE 7: Recovery times in pigs anesthetized with sevoflurane, fentanyl, and vecuronium and undergoing aortic cross-clamping through laparotomy (Group I) or laparoscopy with (Group II) or without aortic cross-clamping (Group III).

\begin{tabular}{lccc}
\hline & & Recovery time $(\mathrm{min})$ & Group III \\
\hline Recovery indicator & Group I & Group II & $10.5 \pm 3.5^{*}$ \\
First movement & $12.5 \pm 8.2$ & $12.6 \pm 10.5$ & $7.5 \pm 1.0$ \\
Extubation & $11.6 \pm 5.8$ & $11.2 \pm 4.1$ & $27.2 \pm 2.3$ \\
Sternal recumbency & $34.7 \pm 23.8$ & $37.4 \pm 14.1$ & $79.3 \pm 15.9^{*}$ \\
\hline
\end{tabular}

${ }^{*}$ Significantly $(P<.05)$ different from values obtained for pigs undergoing laparoscopy.

compression of the splanchnic vascular bed; a sympathetic reflex from the splanchnic regions; and the release of humoral vasoconstriction mediators, such as renin or vasopressin [21-23]. Systemic arterial hypertension has consistently been found during inflation of the peritoneum with $\mathrm{CO}_{2}$, but Huang et al. [24] reported that hypercarbia might not be the major determinant factor of it.

Cross-clamping of the aorta also caused a marked increase in arterial blood pressure, most likely due to the sudden increase in impedance to aortic blood flow and the resultant increase in systolic ventricular wall tension or afterload. However, factors such as myocardial contractility, preload, blood volume, and sympathetic nervous system activation may also be important [25].

Although several clinical reports have noted no significant hemodynamic response to infrarenal cross-clamping $[26,27]$, the hemodynamic response generally consists of increases in arterial pressure (7 to $10 \%$ ) and systemic vascular resistance (20 to $32 \%$ ) with no significant change in heart rate $[9-11,28]$. Cardiac output is generally decreased by $9 \%$ to $33 \%$ [27]. Reported changes in ventricular filling pressures have been inconsistent $[12,27,29]$. Changes in these parameters seen in both groups, in the present study, followed a similar pattern.

Despite the increase in ABP and SVR and the decrease in $\mathrm{CO}$ brought over by pneumoperitoneum creation, these variables' values were similar in groups I and II during aortic cross-clamping. In our opinion, aortic cross-clamping did not greatly affect hemodynamic changes secondary to pneumoperitoneum, as shown by the fact that these variables changed in absence of cross-clamping in Group III.

Regarding ventilatory changes, it is known that if correct ventilatory support is provided, $\mathrm{SpO}_{2}$ can easily be maintained $>90 \%$ during laparoscopy. Carbon dioxide pneumoperitoneum causes absorption of this gas, and if lung ventilation is insufficient to eliminate the absorbed carbon dioxide, hypercapnia will develop, which may cause acidosis, depress myocardial function, and induce arrhythmias and cardiovascular collapse [2]. In view of this possibility, controlled ventilation was used in the present study to prevent hypercapnia, and minute ventilation was adjusted to maintain $\mathrm{EtCO}_{2}$ at $35-40 \mathrm{mmHg}$ throughout the entire procedure, increasing by approximately $30 \%$ (minute ventilation before laparoscopy was $3.6 \pm 0.2 \mathrm{~L} / \mathrm{min}$, and it reached 4.9 $\pm 0,5 \mathrm{~L} / \mathrm{min}$ during laparoscopy) and maintaining a ventilatory rate of $10-12$ breaths/min, as has been previously reported [30,31]. Prior studies [20] reported that insufflation of the peritoneal cavity with $\mathrm{CO}_{2}$ to an intra-abdominal pressure $<15 \mathrm{mmHg}$ does not interfere significantly with pulmonary gas exchange in patients without preexisting cardiopulmonary diseases. Other authors reported a statistically significant correlation between $\mathrm{PaCO}_{2}$ and $\mathrm{EtCO}_{2}$ during 60 minutes of $\mathrm{CO}_{2}$ insufflation [32]. A significant decrease in $\mathrm{pH}$ and concomitant increase in $\mathrm{PaCO}_{2}$ were seen in Group II after clamping, whereas they remained stable in the other two groups at the same time points. These parameters remained changed in this group whilst the aorta was clamped, and they did not regain baseline values until 30 minutes $(\mathrm{pH})$ or 60 minutes $\left(\mathrm{PaCO}_{2}\right)$ after declamping. This could be attributed to the combined effect of aortic clamping and pneumoperitoneum, which could lead to the development of an acidosis of mixed metabolic and respiratory origin. The acidosis seen in Group II was not compensated by the above described ventilatory changes, therefore causing increased bicarbonate values and leading us to consider this mixed metabolic and hypercarbic origin for the acidosis, supporting the prior studies of Tobias et al. [33].

An increase in the partial pressure of arterial carbon dioxide was evidenced in this study. In our opinion, it can be due to $\mathrm{CO}_{2}$ absorption, rather than to the mechanical ventilatory repercussions of increased intra-abdominal pressure [34-36]. It has been previously described that, in healthy patients, absorption of $\mathrm{CO}_{2}$ from the abdominal cavity represents the main (or the only) mechanism responsible for increased $\mathrm{PaCO}_{2}$ [37]. However, in cases of cardiorespiratory compromise, ventilatory changes also contribute significantly to increasing $\mathrm{PaCO}_{2}$ [38]. Therefore, although increased $\mathrm{PaCO}_{2}$ may be well tolerated by young and healthy patients, the extent to which hypercapnia is acceptable has not been determined and probably varies according to the patient's physical status. It is thus wise to maintain $\mathrm{PaCO}_{2}$ within physiologic ranges by adjusting controlled mechanical ventilation [39].

Acute renal failure requiring dialysis is a severe complication in up to $5 \%$ of open aortic surgeries, and it causes high mortality rate [40]. No data about renal failure during laparoscopic aortic surgery could be found in the literature. However, the increased RI evidenced during laparoscopy in this study, both with and without aortic clamping, suggests that its incidence may be higher in this approach than in conventional aortic surgery. There are multiple factors involved in renal failure. On the one hand, aortic cross-clamping elicits marked hemodynamic changes that impact kidney function, increasing renal vascular resistance and markedly 
decreasing blood flow to the renal cortex [37]. On the other hand, the increased intra-abdominal pressure secondary to $\mathrm{CO}_{2}$ insufflation markedly contributes to the significant decrease in renal flow [41], due to vascular compression at the renal parenchyma and the decreased cardiac output seen in the groups undergoing laparoscopy. Despite the absence of permanent renal injury after aortic cross-clamping in either group, careful patient selection for procedures involving laparoscopic aortic cross-clamping is warranted, specially in patients presenting with preexisting nephropathies to avoid further deterioration of their condition.

Recovery was swift in the present study. Mean time to standing was significantly lower in groups II and III (laparoscopy). This is probably attributable to a lesser degree of postoperative pain in animals subjected to laparoscopic surgery, as suggested by the fact that patients subjected to a laparotomy generally complain more of parietal pain (abdominal wall) whereas after laparoscopy, visceral pain is normally present [42].

To our knowledge, we report the first study concerning the physiologic changes occurring during infrarenal aortic surgery using laparoscopic technique. Hemodynamic management of aortic cross-clamping was similar for both surgical approaches in pig [43], however, aortic cross-clamping during laparoscopy causes mixed respiratory and metabolic acidosis that needs to be monitored by arterial gas analysis, even in the absence of abnormal EtCO levels, along with an increasing renal vascular resistance and markedly decreasing blood flow to the renal cortex. Despite being compensated and well tolerated in healthy pigs, this acidosis must be corrected by adjusting controlled mechanical ventilation. Further studies in experimental animal models [44] are required to determine the clinical implication of these findings and their impact in the presence of cardiovascular comorbidity (aortic diseases, hypertension, coronary artery disease, chronic obstructive pulmonary disease, etc.) during aortic surgery.

\section{ACKNOWLEDGMENTS}

The experimental work was performed at the Minimally Invasive Surgery Centre Jesús Usón. Supported by II Plan Regional de Investigación, Desarrollo Tecnológico e Innovación de Extremadura (2001-2004), Consejería de Educación, Ciencia y Tecnología. Junta de Extremadura, Spain. Reference No. 2PR04A024 and by Fondo de Investigación Sanitaria, Instituto de Salud Carlos III, Ministerio de Sanidad y Consumo, Spain. Reference no. PI041172.

\section{REFERENCES}

[1] S. Llagostera-Pujol, J. Dilme-Muñoz, M. Yeste-Campos, J. R. Escudero-Rodríguez, and E. Viver-Manresa, "Cirugía laparoscópica del aneurisma de aorta abdominal," Angiologia, vol. 54, no. 3, pp. 252-258, 2002.

[2] M. S. Carrasco, C. Gomar, M. J. Jiménez, M. F. Martín, and J. R. Lima, "Consideraciones anestésicas en la cirugía endoscópica en humanos," in Aprendizaje y Aplicación de la Anestesia en Cirugóa Toracoscópica, M. S. Carrasco and J. Usón, Eds., pp. 132-135, Edika Med, Barcelona, Spain, 1998.
[3] J. L. Joris, E. E. Hamoir, G. M. Hartstein, et al., "Hemodynamic changes and catecholamine release during laparoscopic adrenalectomy for pheochromocytoma," Anesthesia \& Analgesia, vol. 88, no. 1, pp. 16-21, 1999.

[4] F. Vaquero-Morillo, O. Sanz-Guadarrama, M. J. GonzálezFueyo, J. M. Canga-Presa, and M. C. Fernández-Morán, “Tecnicas de cirugía vascular por laparoscopia: derivación aórtica y simpatectomía lumbar," Angiologia, vol. 54, no. 6, pp. 446454, 2002.

[5] L. Barbera, R. Ludemann, M. Grossefeld, L. Welch, A. Mumme, and L. Swanstrom, "Newly designed retraction devices for intestine control during laparoscopic aortic surgery: a comparative study in an animal model," Surgical Endoscopy, vol. 14, no. 1, pp. 63-66, 2000.

[6] M. Grossefeld, R. Ludemann, B. Geier, L. Barbera, and A. Mumme, "Laparoscopic aortic surgery in a swine model using a newly designed retraction system," Zentralblatt für Chirurgie, vol. 126, no. 2, pp. 126-128, 2001.

[7] Y.-M. Dion, G. W. de Wailly, F. Thaveau, and J. Gourdon, "Totally laparoscopic juxtarenal aortic anastomosis: an experimental study," Surgical Laparoscopy, Endoscopy and Percutaneous Techniques, vol. 13, no. 2, pp. 111-114, 2003.

[8] M. Coggia, I. Javerliat, I. Di Centa, et al., "Total laparoscopic versus conventional abdominal aortic aneurysm repair: a casecontrol study," Journal of Vascular Surgery, vol. 42, no. 5, pp. 906-910, 2005.

[9] S. Gelman, "The pathophysiology of aortic cross-clamping and unclamping," Anesthesiology, vol. 82, no. 4, pp. 10261060, 1995.

[10] H. Askitopolou, C. A. Young, M. Morgan, and M. K. Sykes, "Some cardio-pulmonary effects of infra-renal clamping of the abdominal aorta," Anaesthesia and Intensive Care, vol. 6, no. 1, pp. 44-48, 1978.

[11] D. G. Whalley, F. C. Salevsky, and J. V. Ryckman, "Haemodynamic and metabolic consequences of aortic occlusion during abdominal aortic surgery," British Journal of Anaesthesia, vol. 70, no. 1, pp. 96-98, 1993.

[12] J. M. Gooding, J. P. Archie Jr., and H. McDowell, "Hemodynamic response to infrarenal aortic cross-clamping in patients with and without coronary artery disease," Critical Care Medicine, vol. 8, no. 7, pp. 382-385, 1980.

[13] J. Byrne, J. W. Hallett Jr., and D. M. Ilstrup, "Physiologic responses to laparoscopic aortofemoral bypass grafting in an animal model," Annals of Surgery, vol. 231, no. 4, pp. 512-518, 2000.

[14] P. Alfonsi, A. Vieillard-Baron, M. Coggia, et al., "Cardiac function during intraperitoneal $\mathrm{CO}_{2}$ insufflation for aortic surgery: a transesophageal echocardiographic study," Anesthesia \& Analgesia, vol. 102, no. 5, pp. 1304-1310, 2006.

[15] T. J. Gan, P. S. Glass, A. Windsor, et al., "Bispectral index monitoring allows faster emergence and improved recovery from propofol, alfentanil and nitrous oxide anesthesia," Anesthesiology, vol. 87, no. 4, pp. 808-815, 1997.

[16] N. Tanaka, K. Takeda, S. Nishi, and A. Asada, "A new method for measuring total coronary blood flow using the lithium dilution method," Osaka City Medical Journal, vol. 51, no. 1, pp. 11-18, 2005.

[17] R. S. Sokal and F. J. Rohlf, "Analysis of frequencies," in Biometry: The Principles and Practice of Statistic in Biological Research, pp. 716-721, W. H. Freeman, New York, NY, USA, 2nd edition, 1995.

[18] M. F. Martín-Cancho, J. R. Lima, L. Luis, et al., "Bispectral index, spectral edge frequency $95 \%$ and median frequency 
recorded for various concentrations of isoflurane and sevoflurane in pigs," American Journal of Veterinary Research, vol. 64, no. 7, pp. 866-873, 2003.

[19] P. Alric, F. Ryckwaert, P. Branchereau, C. Marty-Ané, H. Mary, and P. Colson, "A porcine model of systemic and renal haemodynamic responses to infrarenal aortic cross-clamping," European Journal of Vascular and Endovascular Surgery, vol. 25, no. 1, pp. 72-78, 2003.

[20] M. Girardis, U. D. Broi, G. Antonutto, and A. Pasetto, "The effect of laparoscopic cholecystectomy on cardiovascular function and pulmonary gas exchange," Anesthesia \& Analgesia, vol. 83, no. 1, pp. 134-140, 1996.

[21] S. Odeberg, O. Ljungqvist, T. Svenberg, et al., "Haemodymanic effects of pneumoperitoneum and the influence of posture during anesthesia for laparoscopic surgery," Acta Anaesthesiologica Scandinavica, vol. 38, pp. 276-283, 1994.

[22] J. L. Joris, "Anesthetic management of laparoscopy," in Anesthesia, R. D. Miller, Ed., pp. 2011-2029, Churchill Livingstone, New York, NY, USA, 1994.

[23] O. Viinamki and R. Punnonen, "Vasopressin release during laparoscopy: role of increased intra-abdominal pressure," Lancet, vol. 1, no. 8264, pp. 175-176, 1982.

[24] S. J. Huang, C. Y. Lee, F. C. Yeh, and C. L. Chang, "Hypercarbia is not the determinant factor of systemic arterial hypertension during carboperitoneum in laparoscopy," Ma Zui Xue Za Zhi, vol. 29, no. 2, pp. 592-595, 1991.

[25] E. J. Norris, "Anesthesia for vascular surgery," in Miller's Anesthesia, R. D. Miller, Ed., vol. 2, pp. 2070-2089, Churchill Livingstone, Philadelphia, Pa, USA, 6th edition, 2005.

[26] J. K. Lunn, F. J. Dannemiller, and T. H. Stanley, "Cardiovascular responses to clamping of the aorta during epidural and general anesthesia," Anesthesia \& Analgesia, vol. 58, no. 5, pp. 372-376, 1979.

[27] Z. Gamulin, A. Forster, D. Morel, F. Simonet, E. Aymon, and H. Favre, "Effects of infrarenal aortic cross-clamping on renal hemodynamics in humans," Anesthesiology, vol. 61, no. 4, pp. 394-399, 1984.

[28] R. Meloche, T. Pottecher, J. Audet, O. Dufresne, and C. LePage, "Haemodynamic changes due to clamping of the abdominal aorta," Canadian Anaesthetists Society Journal, vol. 24, no. 1, pp. 20-34, 1977.

[29] M. F. Roizen, P. N. Beaupre, R. A. Alpert, et al., "Monitoring with two-dimensional transesophageal echocardiography: comparison of myocardial function in patients undergoing supraceliac, suprarenal-infraceliac, or infrarenal aortic occlusion," Journal of Vascular Surgery, vol. 1, no. 2, pp. 300-305, 1984.

[30] A. J. McMahon, J. N. Baxter, G. Kenny, and P. J. O’Dwyer, "Ventilatory and blood gas changes during laparoscopic and open cholecystectomy," British Journal of Surgery, vol. 80, no. 10, pp. 1252-1254, 1993.

[31] E. A. Hirvonen, L. S. Nuutinen, and M. Kauko, "Ventilatory effects, blood gas changes, and oxygen consumption during laparoscopic hysterectomy," Anesthesia \& Analgesia, vol. 80, no. 5, pp. 961-966, 1995.

[32] T. Yusa, T. Sasara, T. Shimabukuro, and Y. Higa, "Arterial to end-tidal carbon dioxide difference during laparoscopy," $\mathrm{Ma}$ sui, vol. 41, no. 2, pp. 232-237, 1992.

[33] J. D. Tobias, P. Russo, and J. Russo, "An evaluation of acid-base changes following aortic cross-clamping using transcutaneous carbon dioxide monitoring," Pediatric Cardiology, vol. 27, no. 5, pp. 585-588, 2006.
[34] F. S. Bongard, N. A. Pianim, T. A. Leighton, et al., "Helium insufflation for laparoscopic operation," Surgery, Gynecology \& Obstetrics, vol. 177, pp. 140-146, 1993.

[35] B. M. P. Rademaker, J. A. Odoom, L. T. de Wit , C. J. Kalkman, S. A. ten Brink, and J. Ringers, "Haemodynamic effects of pneumoperitoneum for laparoscopic surgery: a comparison of $\mathrm{CO}_{2}$ with $\mathrm{N}_{2} \mathrm{O}$ insufflation," European Journal of Anaesthesiology, vol. 11, no. 4, pp. 301-306, 1994.

[36] B. M. P. Rademaker, J. J. G. Bannenberg, C. J. Kalkman, and D. W. Meyer, "Effects of pneumoperitoneum with helium on hemodynamics and oxygen transport: a comparison with carbon dioxide," Journal of Laparoendoscopic Surgery, vol. 5, no. 1, pp. 15-20, 1995.

[37] L. Andersson, L. Lagerstrand, A. Thörne, A. Sollevi, L.-Å. Brodin, and S. Odeberg-Wernerman, "Effect of $\mathrm{CO}_{2}$ pneumoperitoneum on ventilation-perfusion relationships during laparoscopic cholecystectomy," Acta Anaesthesiologica Scandinavica, vol. 46, no. 5, pp. 552-560, 2002.

[38] C. M. Wittgen, C. H. Andrus, S. D. Fitzgerald, L. J. Baudendistel, T. E. Dahms, and D. L. Kaminski, "Analysis of the hemodynamic and ventilatory effects of laparoscopic cholecystectomy," Archives of Surgery, vol. 126, no. 8, pp. 997-1000, 1991.

[39] J. L. Joris, "Anesthesia for laparoscopic surgery," in Miller's Anesthesia, R. D. Miller, Ed., vol. 2, pp. 2285-2306, Churchill Livingstone, Philadelphia, Pa, USA, 6th edition, 2005.

[40] M. L. Nicholson, D. M. Baker, B. R. Hopkinson, and P. W. Wenham, "Randomized controlled trial of the effect of mannitol on renal reperfusion injury during aortic aneurysm surgery," British Journal of Surgery, vol. 83, no. 9, pp. 12301233, 1996.

[41] C. Are, M. Kutka, M. Talamini, et al., "Effect of laparoscopic antireflux surgery upon renal blood flow," American Journal of Surgery, vol. 183, no. 4, pp. 419-423, 2002.

[42] N. T. Nguyen, S. L. Lee, C. Goldman, et al., "Comparison of pulmonary function and postoperative pain after laparoscopic versus open gastric bypass: a randomized trial," Journal of the American College of Surgeons, vol. 192, no. 4, pp. 469-476, 2001.

[43] M. M. Swindle, A. C. Smith, and B. J. Hepburn, "Swine as models in experimental surgery," Journal of Investigative Surgery, vol. 1, no. 1, pp. 65-79, 1988.

[44] J. Usón-Gargallo, V. Crisóstomo, B. Loscertales, et al., "A new model of abdominal aortic aneurysm with gastric serosa patch: surgical technique and short-term evaluation," Journal of Investigative Surgery, vol. 19, no. 2, pp. 97-104, 2006. 


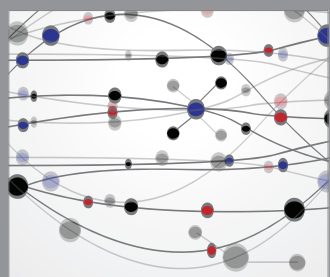

The Scientific World Journal
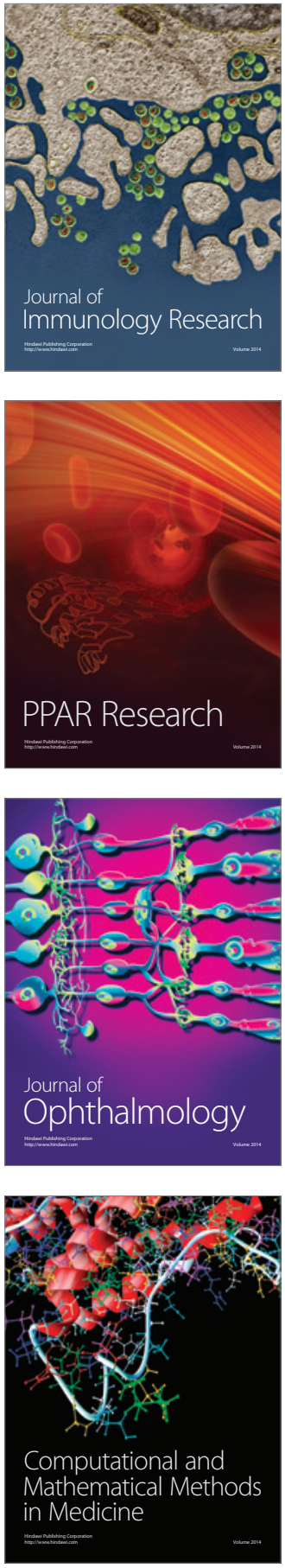

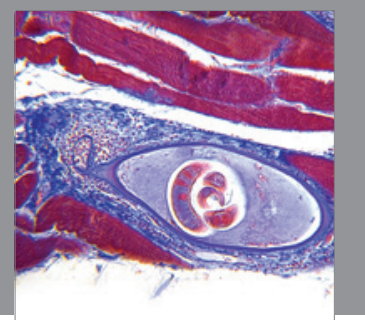

Gastroenterology

Research and Practice
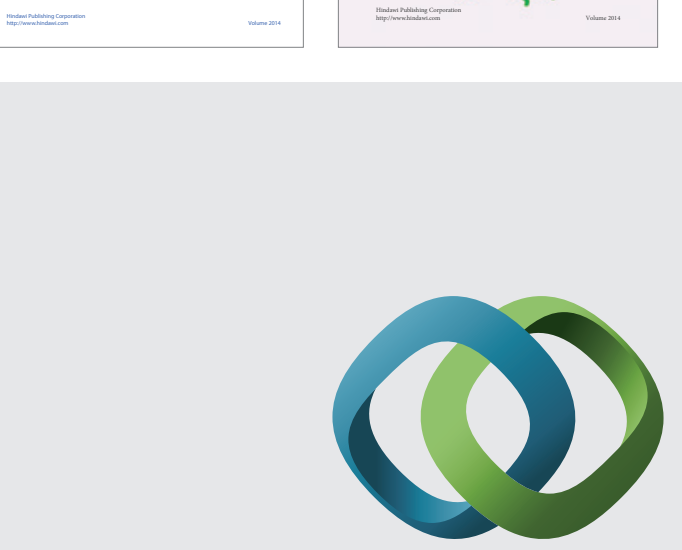

\section{Hindawi}

Submit your manuscripts at

http://www.hindawi.com
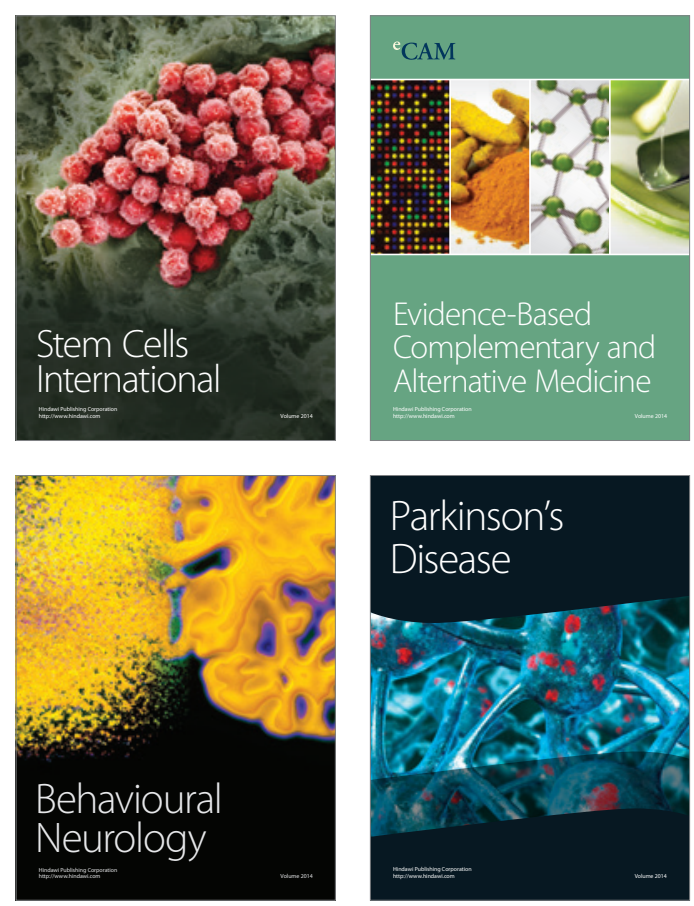

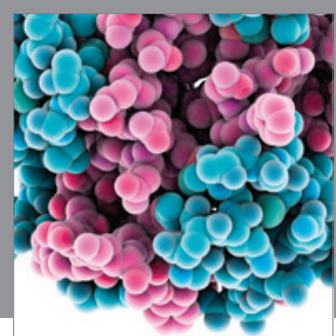

Journal of
Diabetes Research

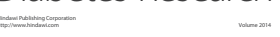

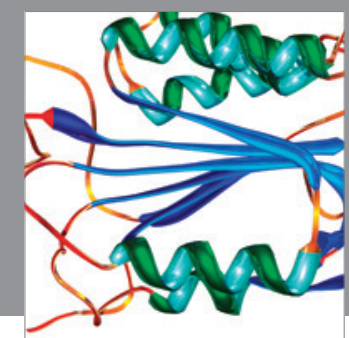

Disease Markers
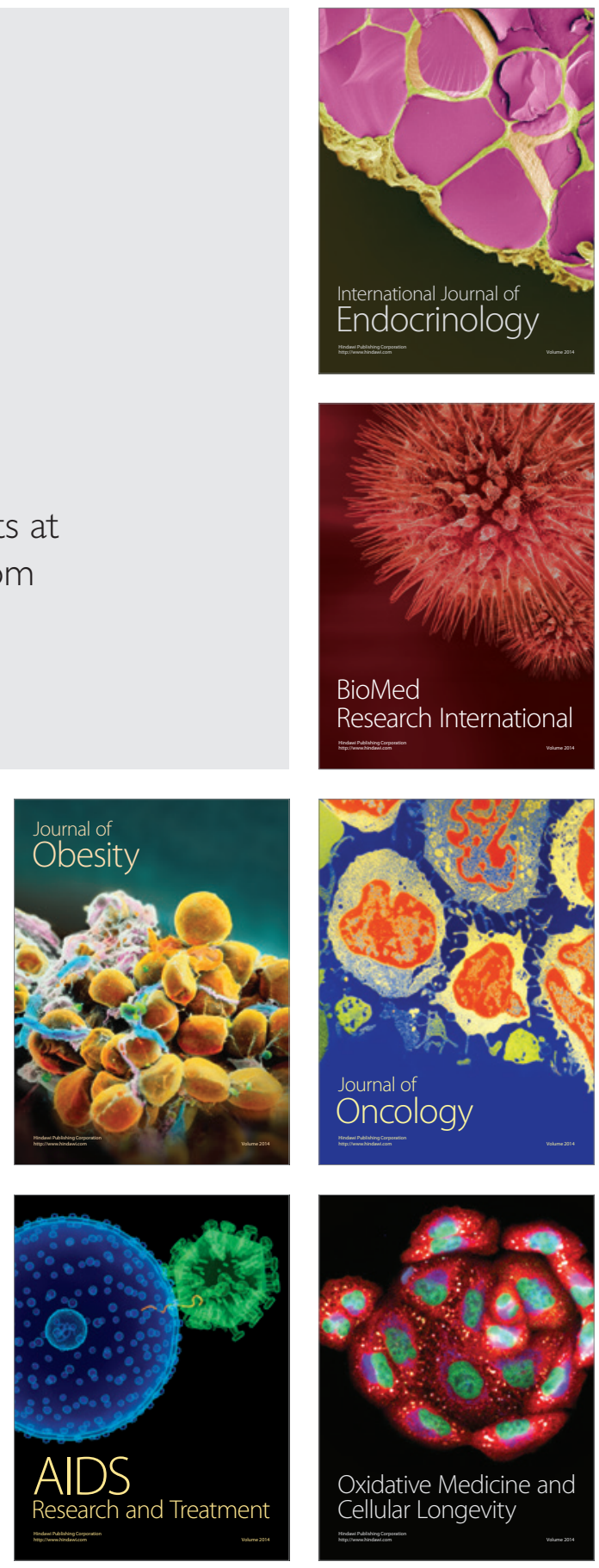